\title{
Monitoramento do fitoplâncton na água bruta da ETA Macapá e inferências sobre a covid-19
}

O fitoplâncton é formado por microalgas e cianobactérias, fornecedores de oxigênio para o meio aquático. Em ecossistemas desequilibrados esses organismos podem se multiplicar e produzir toxinas que afetam a saúde humana e animal. Este estudo teve como objetivo identificar padrões de densidade no fitoplâncton da água bruta da ETAm e relacionar a influência de fatores físicos, químicos e ambientais sobre a densidade das espécies. As amostragens foram realizadas entre maio de 2019 e agosto de 2020 (exceto em março-maio/2020, devido ao isolamento social). Foram identificados 86 táxons: Bacillariophyta (45), Cyanophyta (18), Chlorophyta (10), Charophyta (10), Dinophyta (1), Euglenophyta (1) e Rhodophyta (1), sendo as cianobactérias e diatomáceas os grupos mais abundantes. E as espécies mais abundantes foram Aulacoseira granulata e Limnothrix planctonica, respectivamente. Em relação à densidade de cianobactérias, observou-se que há padrão de aumento no período maio-agosto similar aos anos anteriores (2015-2016). Porém a densidade de cianobactérias observada neste estudo em 2019 (7083,2 cels. mL-1) foi 7x maior que em anos anteriores (1090 cels.mL-1 em 2015), todavia ainda estão em conformidade com os padrões estabelecidos pelo Ministério da Saúde (<10.000 cels.mL-1). Em junho e julho de 2020, quando era esperado o pico de cianobactérias, ocorreu queda expressiva na densidade. Podese inferir que isto ocorreu pela relação entre o aumento do isolamento social em Macapá e a diminuição da abundância de cianobactérias observada neste período de $2020(R 2=0$,94). Quanto à influência dos parâmetros ambientais, a transparência da água foi o parâmetro com maior influência na densidade de cianobactérias.

Palavras-chave: Abastecimento; Cianobactérias; Diatomáceas; Saúde pública.

\section{Monitoring of phytoplankton in the raw water of ETA Macapá and inferences about covid-19}

\begin{abstract}
Phytoplankton is formed by microalgae and cyanobacteria, oxygen suppliers to the aquatic environment. In unbalanced ecosystems these organisms can multiply and produce toxins that affect human and animal health. This study aimed to identify density patterns in phytoplankton from ETAm's raw water and relate the influence of physical, chemical and environmental factors on species density. Samplings were carried out between May 2019 and August 2020 (except in MarchMay/2020, due to social isolation). Eighty-six taxa were identified: Bacillariophyta (45), Cyanophyta (18), Chlorophyta (10), Charophyta (10), Dinophyta (1), Euglenophyta (1) and Rhodophyta (1), with cyanobacteria and diatoms being the most abundant groups. And the most abundant species were Aulacoseira granulata and Limnothrix planctonica, respectively. Regarding the density of cyanobacteria, it was observed that there is an increase pattern in the period MayAugust similar to previous years (2015-2016). However, the density of cyanobacteria observed in this study in 2019 (7083.2 cells. mL-1) was 7x higher than in previous years ( 1090 cells. mL-1 in 2015), but they are still in accordance with the standards established by the Ministry of Health (<10,000 cells.mL-1). In June and July 2020, when the peak of cyanobacteria was expected, there was a significant drop in density. It can be inferred that this occurred due to the relationship between the increase in social isolation in Macapá and the decrease in the abundance of cyanobacteria observed in this period of 2020 (R2 $=0.94)$. As for the influence of environmental parameters, water transparency was the parameter with the greatest influence on the density of cyanobacteria.
\end{abstract}

Keywords: Supply; Cyanobacteria; Diatoms; Public health

Topic: Planejamento, Gestão e Políticas Públicas Ambientais

Reviewed anonymously in the process of blind peer.
Received: 03/03/2021

Approved: 25/03/2021
Elcliane da Costa Cavalcante

Universidade Federal do Amapá, Brasil

http://lattes.cnpq.br/3793855329148285

http://orcid.org/0000-0002-6533-5122

cavalcanteelcli@gmail.com

Silvia Maria Mathes Faustino

Universidade Federal do Amapá, Brasil

http://lattes.cnpq.br/7743053016321109

http://orcid.org/0000-0003-3216-749X

fitomathes@yahoo.com

Luís Maurício Abdon da Silva (i)

Instituto do Estado do Amapá, Brasil

http://lattes.cnpq.br/5915752370566805

http://orcid.org/0000-0001-9510-0933

luis.abdon13@gmail.com

\section{Alan Cavalcanti da Cunha (iD \\ Universidade Federal do Amapá, Brasil \\ http://lattes.cnpq.br/2181817533284030 \\ http://orcid.org/0000-0002-1846-9486 \\ alancunha12@gmail.com}

Elane Domênica Cunha de Oliveira (iD

Instituto do Estado do Amapá, Brasil

http://lattes.cnpq.br/1889117131049535

http://orcid.org/0000-0002-5531-3245

elanedsc@yahoo.com.br
Referencing this:

CAVALCANTE, E. C.; FAUSTINO, S. M. M.; SILVA, L. M. A.; CUNHA, A. C.; OLIVEIRA, E. D. C.. Monitoramento do fitoplâncton na água bruta da ETA Macapá e inferências sobre a covid-19. Revista Ibero Americana de Ciências Ambientais, v.12, n.3, p.664-678, 2021. DOI: http://doi.org/10.6008/CBPC2179-6858.2021.003.0053 


\section{INTRODUÇÃO}

O fitoplâncton compreende um coletivo de microrganismos fotossintetizantes formado pelas microalgas (eucariontes) e cianobactérias (procariontes) que representa o principal fornecedor de oxigênio para o ambiente aquático, além de constituir a base da cadeia alimentar nos ecossistemas aquáticos (REYNOLDS, 2006; PEREIRA, 2013). Dentre os principais fatores que influenciam a produtividade primária pelo fitoplâncton estão: radiação solar, temperatura e principalmente a presença de nutrientes como fósforo e nitrogênio (CALIJURI et al., 2006; ESTEVES, 2011). Em geral, corpos d'água com poucos nutrientes (oligotróficos) apresentam baixa densidade desses organismos ao passo que águas com muitos nutrientes (eutróficas) apresentam elevada densidade do fitoplâncton (CETESB, 2012; SMITH et al., 2009).

O enriquecimento nutricional de ambientes aquáticos é conhecido por eutrofização (SMITH et al., 1999) a qual é considerada uma forma de poluição fruto de fatores naturais decorrentes das chuvas que lavam a superfície terrestre e provocam o aumento da carga nutritiva que chega ao meio aquático, especialmente em ambientes lênticos como os lagos (ESTEVES, 2011). Também pode ter origem artificial, provocada pela intensa atividade antrópica que vem afetando os recursos hídricos devido ao acelerado processo de urbanização. Entre as atividades que mais afetam os ecossistemas aquáticos estão a agricultura, a indústria, e principalmente o despejo de efluentes domésticos nos corpos de água (ESTEVES, 2011; FUNASA, 2014).

Em sistemas de água doce os principais grupos de algas encontrados são: Cyanophyta, Chlorophyta, Euglenophyta, Chrysophyta, Pyrrophyta (ESTEVES, 2011). Em estações de tratamento de água (ETA) alguns desses grupos podem causar a produção de odor, cor ou sabor na água. Além disso, grupos como o das diatomáceas podem provocar o entupimento de filtros (JUN et al., 2001; ROSE et al., 2018) o que pode aumentar os custos com o tratamento da água. Entretanto, em termos sanitários, as cianobactérias são o grupo mais preocupante, uma vez que apresentam a capacidade de produzir toxinas (cianotoxinas) que podem provocar problemas à saúde humana, tanto pela ingestão de água ou alimentos contaminados quanto por contato em atividades de recreação (CALIJURI et al., 2006; BURATTI et al., 2017).

No Brasil, o caso mais preocupante de contaminação por cianotoxinas ocorreu em 1996 em Caruaru$\mathrm{PE}$, onde mais de 50 pacientes de uma clínica de hemodiálise foram a óbito depois de receber tratamento com água contaminada por microcistina, uma toxina produzida por cianobactérias (POURIA et al., 1998; AZEVEDO et al., 2002). A partir deste marco histórico, e a necessidade de enfrentamento do problema associado aos riscos que as cianotoxinas podem oferecer a saúde humana, o governo brasileiro publicou a Portaria de Consolidação no 5 de 28 de setembro de 2017 do Ministério da Saúde, exigindo que os responsáveis por sistemas de abastecimento de água realizem coletas mensais da água bruta para verificar a densidade de células de cianobactérias na água. Além disso, a portaria também exige a identificação dos diferentes gêneros de cianobactérias presentes na captação e a análise da presença de microcistina-LR caso a densidade de células ultrapasse 10.000 células $/ \mathrm{mL}^{-1}$ (BRASIL, 2017).

O Amapá é banhado pelas águas do rio Amazonas e por ser um ambiente lótico com intensa dinâmica 
hidrológica e turbulência não apresenta condições ideais para a existência de florações (CETESB, 2013; OLIVEIRA et al., 2019; ABREU et al., 2020). Apesar disso, o rio Amazonas possui múltiplas funções na orla de Macapá (comércio, navegação, recreação, pesca, etc.), sendo a principal delas o uso para abastecimento de água, que é captada a 500 m da margem, e tratada na Companhia de Água e Esgoto do Amapá (CAESA) (OLIVEIRA et al., 2019). A cidade também não dispõe de um sistema de esgoto eficiente, de forma que por vezes os resíduos sólidos urbanos (RSU), o esgoto doméstico in natura e águas pluviais se misturam sendo despejadas por escoamento superficial diretamente no rio Amazonas. Estudo de simulação de poluentes na zona costeiro-estuarina do Amazonas concluiu que na orla de Macapá estas plumas de poluentes concentram-se próximas da margem, em média $800 \mathrm{~m}$. Isto é, transcendem em extensão o ponto de captação de água bruta, localizada a apenas $500 \mathrm{~m}$ da mesma. Esta hipótese infere que provavelmente os poluentes urbanos afetam diretamente a ETAm e comprometem a qualidade da água captada (PINHEIRO et al., 2008).

Um relatório divulgado pela VIGIAGUA em 2012, mostrou que a CAESA não realizou o monitoramento de cianobactérias na água bruta da estação (BRASIL, 2012). Apesar de antigo não há outros relatórios mais recentes divulgados pela companhia. O único monitoramento que ocorreu na área avaliou a densidade de cianobactérias na ETAm (OLIVEIRA et al., 2019) e revelou baixa densidade de cianobactérias em acordo com o estabelecido pelos padrões do Ministério da Saúde. Além disso, no referido estudo, nenhuma das cepas isoladas apresentou potencial tóxico, isto é, não apresentaram genes associados à produção de toxinas. No entanto, foi detectada a cianotoxina microcistina-LR em baixas concentrações na água bruta e tratada da CAESA (OLIVEIRA et al., 2019b).

Devido aos impactos que o fitoplâncton pode oferecer ao tratamento de água para consumo, este estudo objetivou identificar padrões de densidade no fitoplâncton da água bruta da ETAm e relacionar a influência de fatores físico-químicos e ambientais sobre a densidade das espécies. A principal hipótese da investigação é de que esses organismos se apresentem em baixas densidades e que apresentem estabilidade ao longo do tempo.

\section{MATERIAIS E MÉTODOS}

\section{Caracterização ambiental e delineamento amostral}

A área de estudo fica localizada na cidade de Macapá, capital do estado do Amapá. A coleta das amostras foi realizada na água bruta da Estação de Tratamento de Água de Macapá (ETAm) da Companhia de Água e Esgoto do Amapá (CAESA). A água da ETAm é captada no rio Amazonas, orla de Macapá, próximo ao centro comercial da cidade, à aproximadamente 1000 m de distância da ETAM (Figura 1).

A bacia do rio Amazonas é a maior do mundo e representa cerca de $16-20 \%$ do fluxo de água que flui para os oceanos (SIOLI, 1984; ABREU et al., 2020). O rio Amazonas possui origem na Cordilheira dos Andes de onde transporta elevada carga de sedimentos responsáveis por sua coloração barrenta (SIOLI, 1985; JUNK et al., 2011). Suas águas apresentam pH próximo ao neutro e elevada turbidez, o que é explicado pela alta 
concentração de sólidos em suspensão que apresenta (JUNK et al., 2011).

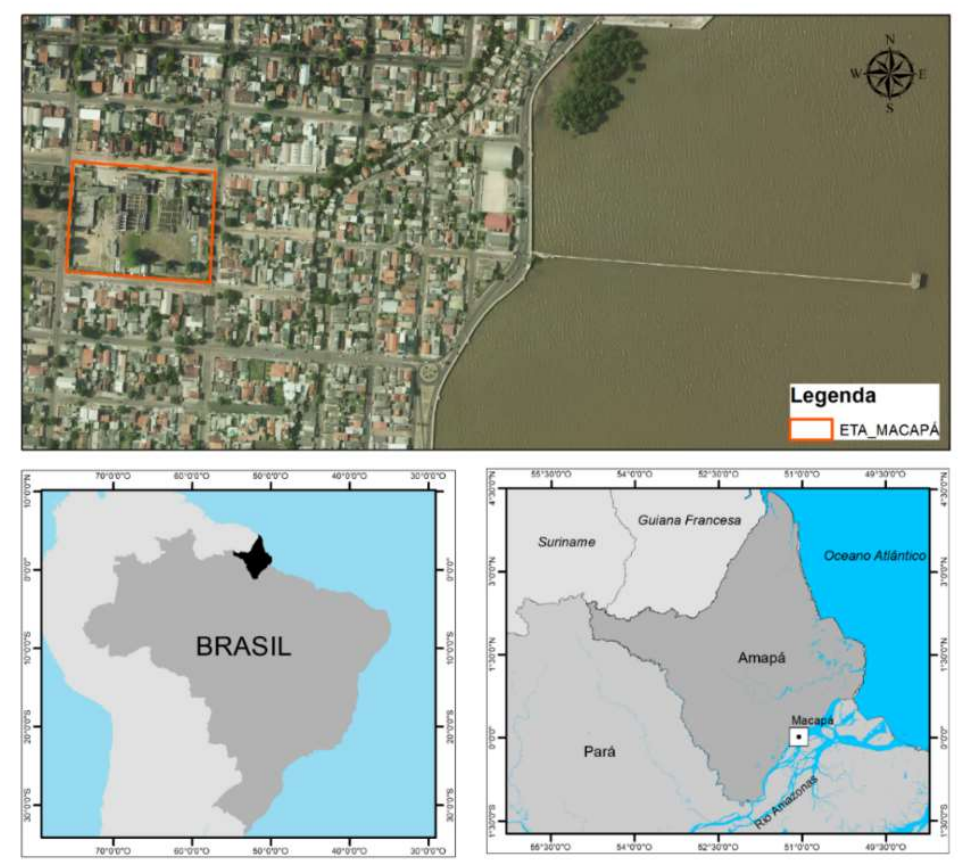

Figura 1: Mapa da área de estudo mostrando a Estação de Tratamento de Água de Macapá (vermelho) localizada a 1000 m do rio Amazonas; localização geográfica da cidade de Macapá do Estado do Amapá.

A amostragem ocorreu entre maio de 2019 a agosto de 2020. Entretanto ressalta-se que nos meses de março, abril e maio de 2020 não foram realizadas em virtude da Pandemia de Coronavírus. As coletas mensais foram realizadas em período da lua-cheia, durante a maré-cheia (preamar), cujas previsões de marés foram obtidas no site da marinha. A maré-cheia possibilita uma melhor visualização dos microrganismos devido a menor quantidade de sólidos em suspensão, o que facilita a visualização do fitoplâncton (OLIVEIRA et al., 2019). Deste modo, foram coletadas amostras de água bruta para contagem do fitoplâncton e análise de parâmetros físico-químicos.

Os parâmetros físico-químicos analisados mensalmente in situ foram condutividade elétrica, sólidos totais dissolvidos, oxigênio dissolvido, temperatura, pH e turbidez (Fig.2). Para as análises foram usados: condutivímetro HI8730 Hanna, Oxímetro YSI, pHmetro portátil e Turbidímetro AP2000 Policontrol. A transparência foi medida na estação com o uso do disco de secchi. Os parâmetros químicos (Cloreto, Ferro, Alumínio, Amônia, Fósforo, Nitrato, Sulfato) foram medidos com o uso do espectrofotômetro DR 3900 Hach no laboratório de Química, Saneamento e Modelagem de Sistemas Ambientais (LQSMSA) da Unifap. Os dados referentes à precipitação total, insolação total e temperatura média máxima foram solicitados do Núcleo de Hidrometeorologia e Energias Renováveis (NHMET).

\section{Contagem do fitoplâncton}

As amostras destinadas a contagem do fitoplâncton foram fixadas com solução de lugol $(7 \mathrm{~mL}$ para 1L). A contagem ocorreu pelo método de sedimentação em câmaras de Utermöhl de $5 \mathrm{~mL}$. Este volume foi considerado o mais adequado, uma vez que a visualização do fitoplâncton fica prejudicada em volumes maiores devido à elevada concentração de sólidos presentes na água (OLIVEIRA et al., 2019). O tempo de 
sedimentação adotado foi de cerca de 24 horas.

A contagem dos organismos foi realizada com o auxílio do microscópico invertido Axiovert A1 (Zeiss, Alemanha) com sistema de aquisição de imagens Zen Lite, com aumento de 400x. Durante o procedimento foi realizada a contagem de células para as cianobactérias e de indivíduos para microalgas. Isso ocorreu porque a Portaria de Consolidação no 5 do Ministério da Saúde exige a contagem de células apenas para cianobactérias, não fazendo menção aos demais organismos do fitoplâncton (BRASIL, 2017). A identificação do fitoplâncton foi realizada por morfologia com o uso de bibliografias especializadas: Bicudo et al. (2006), e artigos retirados de plataformas como: ResearchGate, Electronic Library Online (SciELO), e ScienceDirect.

\section{Relação isolamento social $x$ densidade de cianobactérias}

Com o objetivo de avaliar a existência de relação entre isolamento social e a densidade de cianobactérias, foram levantados os valores diários do Índice de Isolamento Social ${ }^{1}$ e calculada a média mensal para o município de Macapá em junho, julho e agosto de 2020. O site mostra o percentual da população que está respeitando a recomendação de isolamento, e seus dados servem para auxiliar as autoridades a direcionarem os recursos de segurança pública, comunicação e saúde.

\section{Influência das variáveis ambientais sobre o fitoplâncton}

Para avaliar a influência das variáveis ambientais sobre o fitoplâncton foi realizada a análise de correspondência canônica (CCA) conforme recomendações de Braak et al. (1995). Foram utilizados dados de abundância relativa do fitoplâncton, sendo excluídas da análise as espécies com densidade $\leq 10 \%$ da densidade total ou com frequência de ocorrência $<20 \%$. Inicialmente, foi realizada a transformação de $L n$ $(x+1)$ em dados biológicos e ambientais. Em seguida, foi feita uma seleção das variáveis físico-químicas a serem utilizadas na CCA, para que assim fossem removidas da análise as variáveis irrelevantes ou redundantes, fatores ambientais colineares ou com menor variação (BRAAK et al., 1995). Essa seleção foi realizada por meio da função "ordistep" do pacote vegan, software R 3.4.3 (R DEVELOPMENT CORE TEAM, 2017). Os testes de permutação (anova.cca, função R) foram aplicados para testar a significância do modelo, dos eixos e dos parâmetros ambientais selecionados. Além disso, foi calculado o fator de inflação (VIF), sendo eliminadas as variáveis que apresentavam VIF $\geq 15$, eliminando-se variáveis multicolineares (OKSANEN, 2012). Após a triagem, a CCA foi realizada no software Past 3.19. Também foi realizada uma análise de correlação de Spearman com todas as variáveis ambientais (matriz cheia) para verificar quais se relacionaram com os parâmetros selecionados pela CCA e assim obter uma melhor interpretação dos resultados.

\section{RESULTADOS}

\section{Parâmetros físico-químicos}

Alguns parâmetros não diferiram significativamente ao longo do monitoramento, como a

\footnotetext{
${ }^{1}$ https://mapabrasileirodacovid.inloco.com.br/pt/
} 
temperatura da água, com $28,3 \pm 1,3{ }^{\circ} \mathrm{C}$, com máxima em setembro $\left(30,3{ }^{\circ} \mathrm{C}\right)$; a insolação total $(7,2 \pm 1,9 \mathrm{~h})$ com picos no período de agosto-novembro de 2019; e a temperatura média máxima do ar $\left(32,6 \pm 1,1{ }^{\circ} \mathrm{C}\right)$. A concentração de oxigênio dissolvido (OD) foi em média de $6,0 \pm 0,7 \mathrm{mg} \mathrm{L}^{-1}$, e o pH se manteve próximo ao neutro, com 6,4 $\pm 0,4$. As concentrações de nutrientes foram em média de $1,2 \pm 0,4 \mathrm{mg} \mathrm{L}^{-1}$ de ferro (Fe); $0,7 \pm 0,3$ $\mathrm{mg} \mathrm{L}^{-1}$ de amônia $\left(\mathrm{NH}_{3}\right) ; 0,4 \pm 0,1 \mathrm{mg} \mathrm{L}^{-1}$ de ortofosfato $(\mathrm{P}) ; 0,5 \pm 0,4 \mathrm{mg} \mathrm{L}^{-1}$ de nitrato $\left(\mathrm{NO}_{3}\right)$; e 1,9 $\pm 1,9 \mathrm{mg} \mathrm{L}^{-1}$ de sulfato.

Outros parâmetros apresentaram significativa variação ao longo do estudo. Destaca-se a transparência, com média $30,2 \pm 6,9 \mathrm{~cm}$. Esta média foi maior no período entre maio e novembro. $A$ condutividade média foi de $43,9 \pm 7,9 \mu \mathrm{S} \mathrm{cm}^{-1}$. Os parâmetros sólidos totais dissolvidos médios (TDS) foi de 20,4 $\pm 4,4$ ppm, com máximos em novembro (30 ppm) e mínimos em setembro (10 ppm); e a turbidez foi de

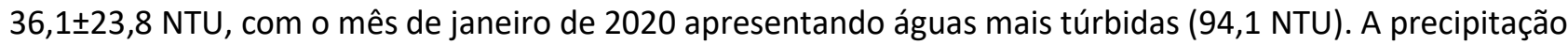
média mensal foi de $199 \pm 140,8 \mathrm{~mm}$, com o mês de maio apresentando o maior volume de chuva $(476,5 \mathrm{~mm})$, e o mês de setembro $(5,0 \mathrm{~mm})$ e outubro $(6,9 \mathrm{~mm})$ sendo os menos chuvosos. O cloreto apresentou concentração média de $5,8 \pm 4,4 \mathrm{mg} \mathrm{L}^{-1}$. Observa-se que todos os parâmetros observados estão de acordo com o estabelecido na legislação brasileira (Tabela 1) (BRASIL, 2005; BRASIL, 2017).

Tabela 1: Resultados dos parâmetros físico-químicos da água bruta da ETAm.

\begin{tabular}{|c|c|c|c|}
\hline Parâmetros & Média \pm sd & Mínima & Máxima \\
\hline Transparência $(\mathrm{cm})$ & $30,2 \pm 6,9$ & 15 & 39 \\
\hline Condutividade $\left(\mu \mathrm{S} \mathrm{cm}^{-1}\right)$ & $43,9 \pm 7,9$ & 30 & 60 \\
\hline TDS (ppm) & $20,4 \pm 4,4$ & 10 & 30 \\
\hline Turbidez (NTU) & $36,1 \pm 23,8$ & 22,1 & 94,1 \\
\hline $\mathrm{OD}\left(\mathrm{mg} \mathrm{L}^{-1}\right)$ & $6,0 \pm 0,7$ & 4,86 & 6,8 \\
\hline Temperatura (으) & $28,3 \pm 1,3$ & 25,6 & 30,3 \\
\hline $\mathrm{pH}$ & $6,4 \pm 0,4$ & 5,7 & 7,1 \\
\hline Precipitação Total (mm) & $199 \pm 140,8$ & 5 & 476,5 \\
\hline Insolação Total (h) & $7,2 \pm 1,9$ & 3,9 & 9,6 \\
\hline T média máxima ${ }^{\circ} \mathrm{C}$ & $32,6 \pm 1,1$ & 31 & 34,3 \\
\hline Cloreto (mg L-1) & $5,8 \pm 4,4$ & 2,1 & 16,3 \\
\hline Ferro $\left(\mathrm{mg} \mathrm{L}^{-1}\right)$ & $1,2 \pm 0,4$ & 0,34 & 2,14 \\
\hline Alumínio (mg L-1) & $0,1 \pm 0,0$ & 0,023 & 0,09 \\
\hline Amônia $\left(\mathrm{mg} \mathrm{L}^{-1}\right)$ & $0,7 \pm 0,3$ & 0,36 & 1,4 \\
\hline Ortofosfato (mg L-1) & $0,4 \pm 0,1$ & 0,19 & 0,56 \\
\hline Nitrato (mg L-1) & $0,5 \pm 0,4$ & 0 & 1,3 \\
\hline Sulfato $\left(\mathrm{SO}_{4}\right)\left(\mathrm{mg} \mathrm{L}^{-1}\right)$ & $1,9 \pm 1,9$ & 0 & 5 \\
\hline
\end{tabular}

\section{Contagem e densidade do fitoplâncton}

Durante o monitoramento foram observados 86 táxons, pertencentes às divisões Bacillariophyta (45), Cyanophyta (18), Chlorophyta (10), Charophyta (10), Dinophyta (1), Euglenophyta (1) e Rhodophyta (1) (Figura 2).

Quanto à densidade de organismos, junho de 2019 foi o mês que apresentou a maior densidade (280,3 ind. $\left.\mathrm{mL}^{-1}\right)$. Nas demais amostras a densidade foi baixa, com o mês de dezembro de 2019 alcançando 24,0 ind. $\mathrm{mL}^{-1}$; e julho de 2020 apresentando a menor densidade de organismos (22,8 ind. $\mathrm{mL}^{-1}$ ) (Figura 3).

Quanto à abundância, dois grupos do fitoplâncton foram os mais significativos durante o estudo: Bacillariophyta (diatomáceas) e Cyanophyta (cianobactérias) (Figura 4). Os demais grupos foram pouco abundantes. A divisão Bacillariophyta dominou o fitoplâncton em quase todo o período de estudo (setembro 
de 2019 a agosto de 2020), representando $\geq 50 \%$ da densidade de todas as espécies.

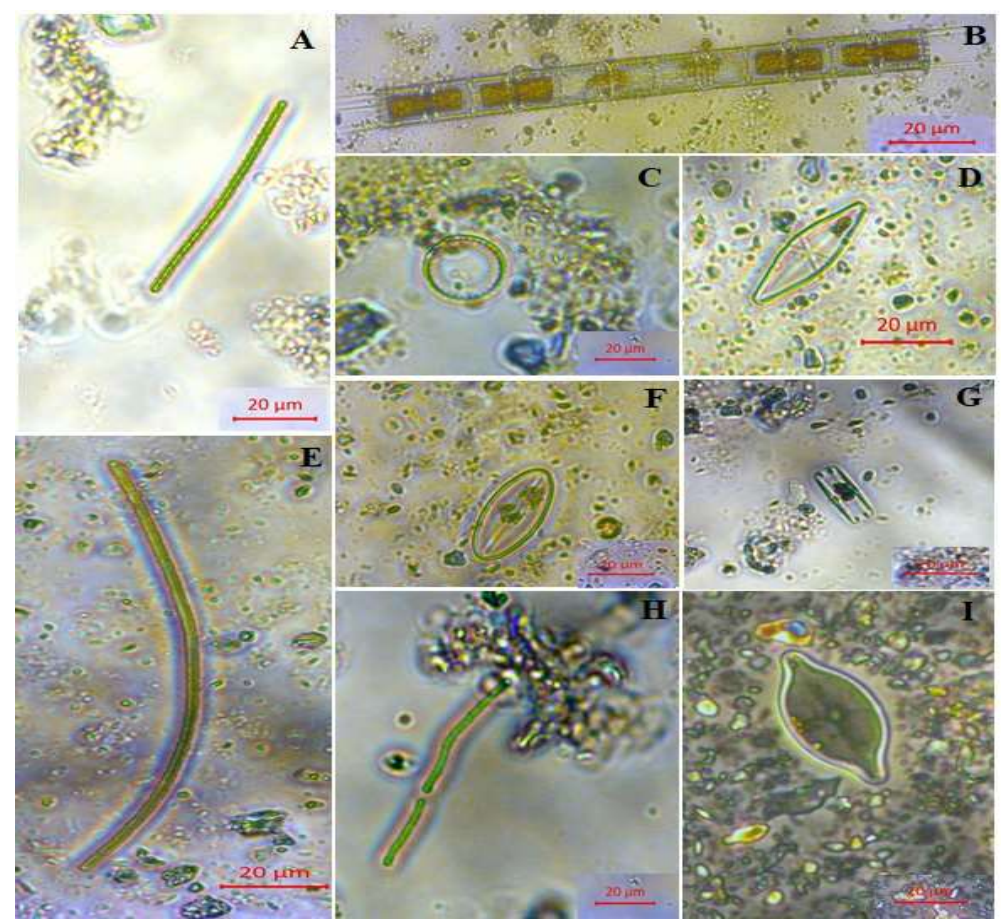

Figura 2: Fotomicrografias de algumas das espécies mais frequentes A) Alkalinema pantanalense; B) Aulacoseira granulata; C) Cyclotella sp.; D) Capartogramma sp.; E) Limnothrix planctonica sp.; F) Diploneis; G) Eunotia sp.; H) Leptolyngbya sp.; I) Placoneis sp.

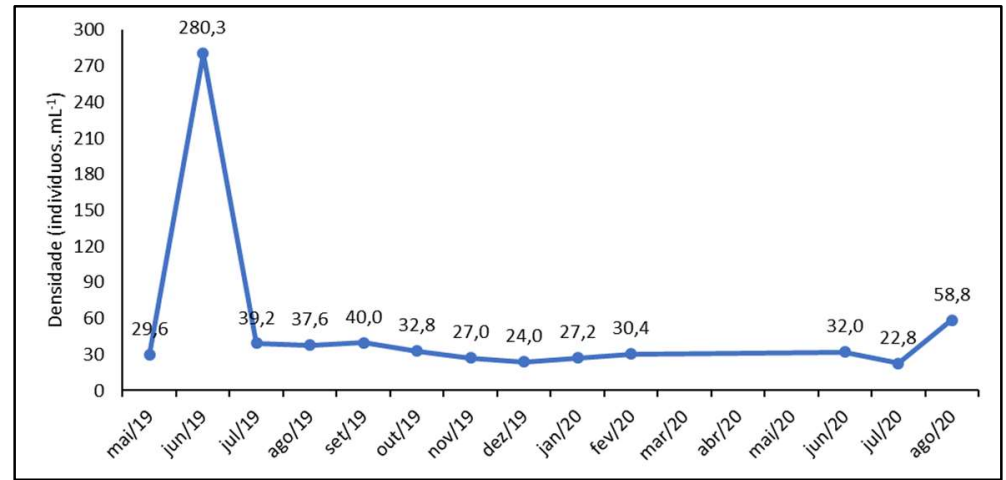

Figura 3: Número de indivíduos por $\mathrm{mL}^{-1}$ nas amostras do período de estudo.

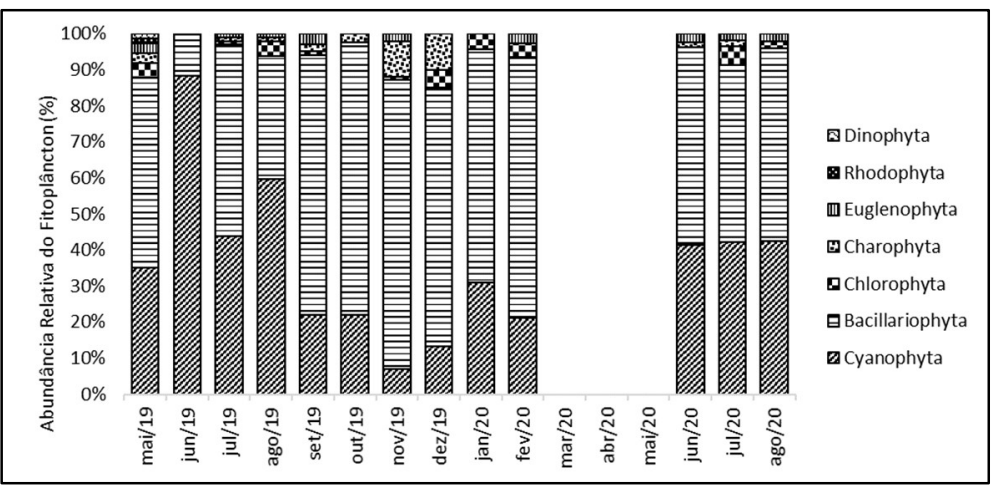

Figura 4: Abundância relativa do fitoplâncton da água bruta da ETAm.

Este grupo só não foi dominante em junho de 2019 e agosto de 2019 quando foi observada dominância da divisão Cyanophyta. Desses grupos, a espécie Aulacoseira granulata foi a diatomácea mais abundante, sendo observada principalmente em setembro de 2019. Porém, esta espécie não foi dominante em nenhum dos meses analisados. 
Todavia, para a divisão Cyanophyta, a espécie mais abundante foi Limnothrix planctonica, sendo dominante em junho de 2019 ( $88 \%$ da densidade total da amostra) e agosto de 2019 (60\% da amostra). As espécies Aulacoseira granulata e Limnothrix planctonica ocorreram em 100\% das amostras.

\section{Densidade de células de cianobactérias}

O monitoramento da densidade de células de cianobactérias (cels. $\mathrm{mL}^{-1}$ ) foi realizado conforme estabelecido pela Portaria no 5 do Ministério da saúde (BRASIL, 2017). As maiores densidades de cianobactérias foram observadas em junho de 2019 (7083,2 cels. mL $\left.{ }^{-1}\right)$, agosto de 2019 (623,2 2019 cels. mL $\left.{ }^{1}\right)$ e agosto de $2020\left(603,8\right.$ cels. $\left.\mathrm{mL}^{-1}\right)$. Em novembro ocorreu a menor densidade de células (44 cels. $\left.\mathrm{mL}^{-1}\right)$ (Figura 5). Apesar dos valores estarem em conformidade com o estabelecido em legislação é preciso ressaltar que em junho de 2019 ocorreu um crescimento acentuado no número de células, alcançando até 7083,2 cels. $\mathrm{mL}^{-1}$. Este valor se aproxima bastante daquele estabelecido pelo Ministério da Saúde (10.000 cels. $\left.\mathrm{mL}^{-1}\right)$.

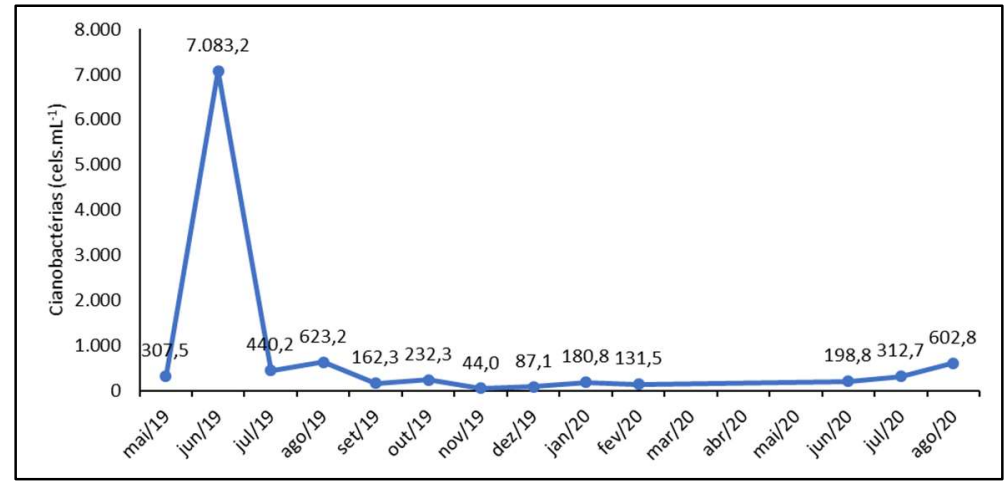

Figura 5: Monitoramento de células de cianobactérias dos meses de estudo 2019/2020.

A abundância de cianobactérias foi maior no período de maio-agosto de 2019. Esses resultados são similares aos encontrados em 2015 no mesmo local de amostragem, com pico de cianobactérias (especialmente Limnothrix planctonica) no trimestre maio a agosto (OLIVEIRA et al., 2019) (Figuras 6 e 7 ).

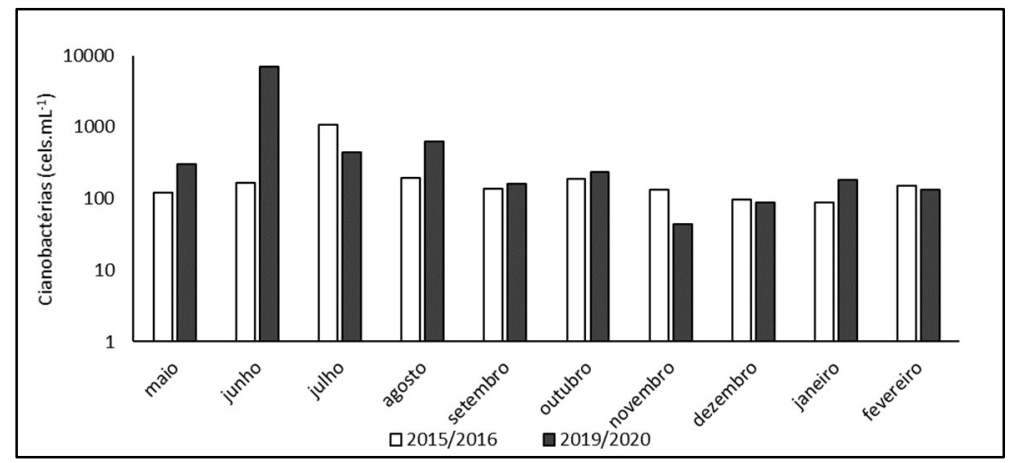

Figura 6: Comparação da abundância de cianobactérias dos anos 2015/2016 e 2019/2020.

A comparação temporal da densidade de cianobactérias observada neste estudo (2019/2020) com a densidade observada em anos anteriores (2015/2016), mostra que houve um aumento de 7x do pico de cianobactérias registrado em 2015 (1090 cels. mL ${ }^{-1}$ ) para o registrado neste estudo em 2019 (7083,2 cels. mL ${ }^{1}$ ) (Figura 7). Em ambos os estudos a maior densidade de cianobactérias ocorreu no período de maio a agosto. Apesar do aumento observado em 2019, o monitoramento dos meses de junho e julho de 2020 
mostrou que este aumento não se manteve, pois houve uma queda acentuada na densidade de células (junho de 2020-198,8 células.mL ${ }^{-1}$; julho de 2020-312,68 células. mL ${ }^{-1}$ ) (Figura 7). No entanto, em agosto de 2020 voltou a ocorrer aumento na densidade de células de cianobactérias $\left(602,8 \mathrm{cels}\right.$. $\left.\mathrm{mL}^{-1}\right)$, apresentando resultado semelhante ao observado em agosto de $2019\left(623,2\right.$ cels. $\left.\mathrm{mL}^{-1}\right)$.

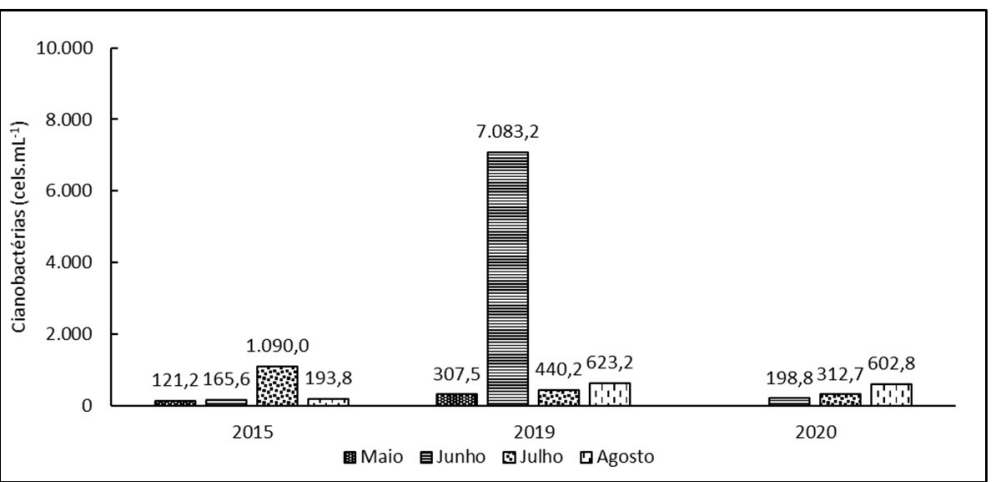

Figura 7: Comparação da abundância de cianobactérias no período maio-agosto dos anos de 2015, $2019,2020$.

As espécies de cianobactérias encontradas durante os dois anos de monitoramento foram: Alkalinema pantanalense, Anabaena sp., Aphanizomenon sp., Borzia brevis Cephalothrix sp., Dolichospermum planctonicum, Dolichospermum sp., Geitlerinema splendidum, Komvophoron sp., Leptolyngbya sp., Limnothrix planctonica, Merismopedia sp., Pseudanabaena sp. Raphidiopsis mediterranea, Phormidium sp., e Scytolyngbya sp., Stigonema sp. e uma espécie identificada como morfoespécie 1.

Com relação a abundância relativa de cianobactérias, foi observado que a espécie Limnothrix planctonica foi a mais abundante nas amostras, com exceção do mês de maio de 2019 no qual foi observado maior abundância da espécie Alkalinema pantanalense $\left(184,7\right.$ cels. $\left.\mathrm{mL}^{-1}\right)$. As espécies menos abundantes foram Aphanizomenon sp., Komvophoron sp., Dolichospermum planctonicum, Pseudanabaena sp. e morfoespécie 1.

Para avaliar se a densidade de cianobactérias teria aumentado ao longo dos anos, assim como foi registrado em anos anteriores (2015 e 2019) (OLIVEIRA et al., 2019), foram realizadas coletas adicionais em junho, julho e agosto de 2020, período em que era esperado o pico de densidade das cianobactérias. Surpreendentemente, as amostras de junho e julho de 2020 apresentaram uma queda expressiva no número de cianobactérias. Por outro lado, em agosto 2020, a abundância de cianobactérias foi similar aos picos de anos anteriores (Figura 7). Adicionalmente, foi avaliada a existência de uma correlação entre o índice de isolamento social no município de Macapá e a abundância de cianobactérias observada durante os meses de junho, julho e agosto de 2020 (Figura 8). Os resultados indicaram que existe correlação entre índice de isolamento social e a densidade de cianobactérias $\left(R^{2}=0,94\right)$. Durante os meses de junho e julho, com maiores índices de isolamento social, a abundância de cianobactérias foi baixa. Por outro lado, quando o índice de isolamento social diminuiu, como ocorreu por volta do mês de agosto, a abundância de cianobactérias aumentou (Figura 8). 


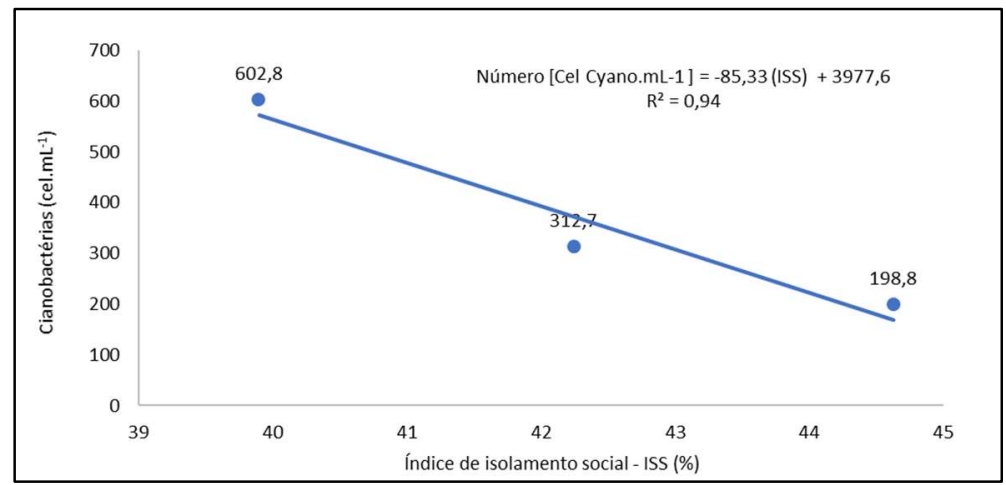

Figura 8: Relação entre o índice de isolamento social e a abundância de cianobactérias observada nos meses de junho, julho e agosto de 2020- final do primeiro período de isolamento social devido à pandemia de Covid19.

\section{Relação entre o fitoplâncton e os parâmetros ambientais}

A análise de correspondência canônica (CCA) foi realizada para que fosse possível estimar a relação entre as variáveis ambientais e a abundância do fitoplâncton. A CCA foi realizada com cinco variáveis ambientais (transparência, precipitação máxima, oxigênio dissolvido, temperatura da água e ferro), e seis espécies do fitoplâncton com maior abundância ou frequência de ocorrência (Aulacoseira granulata, Aulacoseira sp., Cyclotella sp., Eunotia sp., Limnothrix planctonica e Alkalinema pantanalense) identificadas ao longo do estudo.

Os dois eixos da CCA juntos explicaram 94,49\% da relação entre a densidade do fitoplâncton e as variáveis ambientais, sendo o eixo CA1 o que mais explicou essa relação (55\%) enquanto que o eixo CA2 explicou apenas 39,49\% (Figura 9). 0 teste de permutação mostrou que o modelo foi significativo $(p=0,003)$, assim como os dois primeiros eixos da CCA com $p=0,008$ para o CA1, e $p=0,002$ para o CA2. Todas as variáveis escolhidas foram significativas $(p<0,05)$ e apresentaram $\mathrm{VIF}<15$.

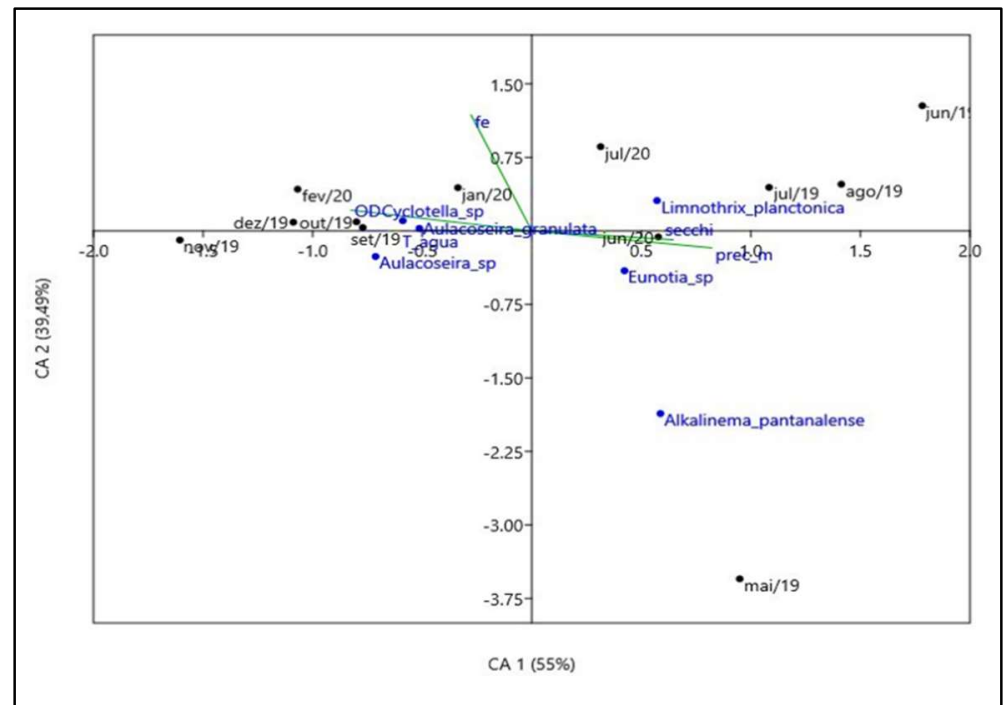

Figura 9: Análise de correspondência canônica (CCA) mostrando a correlação entre as variáveis ambientais e o fitoplâncton.

O eixo CA1 apresentou maior correlação com as variáveis ambientais mostrando um padrão de variação sazonal, no qual foi observado o domínio da divisão Bacillariophyta durante os meses menos chuvosos do ano (setembro-fevereiro) e dominância da divisão Cyanophyta no período chuvoso (maio- 
junho). Vale ressaltar que o inverno amazônico ocorre de janeiro-maio e os meses de junho e julho representam períodos de transição entre os meses chuvosos e o período de seca. Entretanto como não foram realizadas coletas dos meses de março-abril, o período de maio a junho foi identificado como o mais chuvoso na CCA (Figura 9).

No lado direito do eixo CA1 observa-se que as variáveis precipitação máxima e transparência influenciaram positivamente a abundância das espécies Eunotia sp. e Limnothrix planctonica, especialmente no período de maio-agosto de 2019 e junho-julho de 2020. Esses resultados também foram observados em 2015 quando a variável transparência esteve fortemente relacionada à abundância de Limnothrix planctonica durante os meses de junho de julho (OLIVEIRA et al., 2019), o que evidencia forte relação entre a abundância dessa espécie com a transparência da água. No lado oposto do eixo CA1 (esquerdo) as variáveis oxigênio dissolvido e temperatura da água apresentaram forte correlação com a abundância das espécies Aulacoseira granulata, Aulacoseira sp. e Cyclotella sp. Essa relação ocorreu principalmente no mês de setembro de 2019 a fevereiro de 2020 período em que foi observada dominância $(\geq 50)$ da divisão Bacillariophyta.

O eixo CA2 não explicou muito a relação entre a abundância dos organismos com as variáveis ambientais. Este apresentou maior correlação com os parâmetros ferro ( $\mathrm{Fe})$, transparência e temperatura da água. Os dois últimos influenciaram positivamente a abundância da espécie Alkalinema pantanalense, que apresentou maior abundância durante o mês de maio de 2019.

Os resultados da correlação de Spearman são mostrados na figura 10 onde estão apresentados os fatores físicos e químicos que se relacionaram positiva (azul) e negativamente (vermelho) com as variáveis ambientais selecionadas. Os resultados mostram que as variáveis insolação e temperatura máxima se correlacionaram de forma positiva à variável transparência, a qual influenciou a abundância da espécie Limnothrix planctonica, especialmente no mês de junho de 2019.

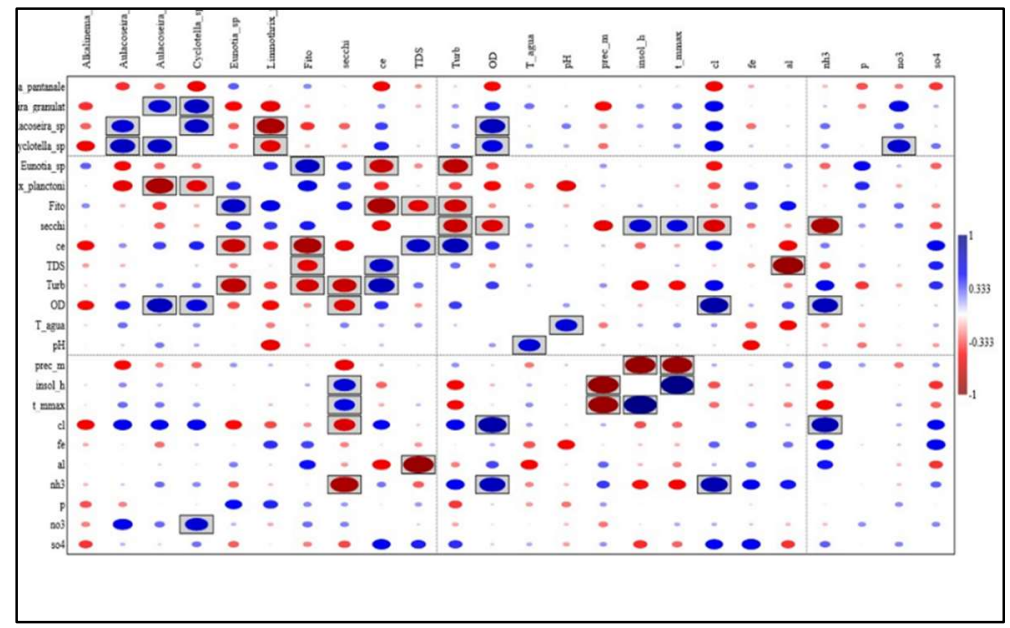

Figura 10: Correlação de Spearman apresentado os fatores físicos e químicos que se relacionaram com as variáveis ambientais (azul: correlação positiva) e (vermelho: correlação negativa). Os quadrados indicam correlações significativas $(p<0,05)$.

\section{DISCUSSÃO}

Os grupos encontrados durante o monitoramento são organismos comuns em ambientes de água doce e já foram documentados em estudos na região Amazônica (CUNHA et al., 2013). A densidade do 
fitoplâncton foi baixa ao longo do período de estudo. A elevada turbulência e turbidez do rio Amazonas (ABREU et al., 2020) podem ser fatores que expliquem essa baixa densidade, uma vez que fortes correntezas e baixa penetração de luz no corpo d'água podem dificultar o crescimento das populações do fitoplâncton, como já foi observado em estudos de rios com características parecidas com as do Amazonas (FISHER, 1978; CUNHA et al., 2013; SILVA et al., 2018).

Ocorreu um único registro de crescimento acentuado na densidade de organismos em junho de 2019, quando a amostra foi dominada por cianobactérias da espécie Limnothrix planctonica $\left( \pm 7.000\right.$ cels. $\mathrm{mL}^{-}$ $\left.{ }^{1}\right)$. Apesar da elevada densidade, os valores ainda estão em conformidade com a recomendação do Ministério da Saúde $\left(<10.000\right.$ cels. $\mathrm{mL}^{-1}$ ) (BRASIL, 2017). No entanto, é preciso ressaltar que o acréscimo do número de células de cianobactérias registrado no estudo foi marcante quando comparado ao mesmo período em 2015, que apresentou número máximo de \pm 1.000 cels. $\mathrm{mL}^{-1}$; ocasião em que foi detectada a cianotoxina microcistina (OLIVEIRA et al., 2019).

Com relação à densidade de cianobactérias do período junho-agosto de 2020, os resultados indicam uma potencial correlação entre a diminuição de pessoas nas ruas em virtude da Pandemia de Coronavírus e a queda na abundância de cianobactérias na ETAm no período em que era esperado o seu pico de densidade (junho-julho). Pode-se inferir que a diminuição de pessoas circulando na orla de Macapá até meados de julho, resultaram numa redução do despejo de poluentes na água e ruas da cidade. Como a concentração de poluentes é um dos principais fatores responsáveis pela presença desses organismos nos corpos d'água (SMITH et al., 2009), sua diminuição devido a menor circulação de pessoas pode ter provocado queda na densidade de cianobactérias na água.

Em 2020 foi observado em muitos países uma diminuição nos índices de poluição tanto do ar como também de ecossistemas aquáticos, como consequência das medidas de restrição de mobilidade de pessoas nas ruas com o objetivo de se evitar a transmissão pelo Coronavírus (YUNUS et al., 2020; HE et al., 2020). Acredita-se que pode ter ocorrido situação semelhante na área de estudo. As medidas de isolamento social em Macapá foram mais rígidas até o final de junho/2020, e depois iniciou-se a flexibilização no meio do mês de julho/2020, com flexibilização maior em agosto/2020.

Devido ao risco de contágio pelo Covid-19, após o início da flexibilização (principalmente após o mês de agosto) a orla da cidade despontou como primeira opção de local para passeios, de forma que lá ocorreu uma grande aglomeração de pessoas. A cidade de Macapá não dispõe de um sistema de esgoto eficiente e o saneamento básico é ainda precário de forma que, por vezes, poluentes são despejados no rio ou são transportados ao mesmo pela ação das chuvas. Estudos realizados no Amazonas já detectaram poluição de cunho microbiológico (CUNHA et al., 2004; CUNHA et al., 2005), que pode chegar ao ponto de captação e comprometer a qualidade da água e a saúde da população (DAMASCENO et al., 2015).

Os resultados da CCA apontam para a existência de um padrão de variação sazonal no qual dois grandes grupos do fitoplâncton se mostram abundantes: Bacillariophyta que dominou durante os períodos menos chuvosos do ano, e a divisão Cyanophyta cuja dominância ocorreu no período de transição entre o período chuvoso e o menos chuvoso (maio-agosto). 
As diatomáceas (Bacillariophyta) são comuns em ecossistemas lóticos (SOARES et al., 2007) e adaptadas a ambientes lóticos e baixa disponibilidade de luz (BORGES et al., 2008). Estudos realizados em rios com características semelhantes às do Amazonas também observaram dominância deste grupo nos períodos mais secos do ano (SILVA et al., 2018). Com isso, acredita-se que a dominância das diatomáceas nas amostras ocorreu devido a sua capacidade de se adaptar às características hidrodinâmicas do rio Amazonas. Nesse estudo a principal representante do grupo foi a espécie Aulacoseira granulata, que é geralmente associada a ecossistemas com mistura de coluna d'água e sujeitos à eventos erosivos (COSTA-BODDEKER et al., 2007; BICUDO et al., 2016), característica comum do Rio Amazonas (SIOLI, 1985; JUNK et al., 2011).

No período de transição entre a estação chuvosa e seca, nos quais a divisão Cyanophyta foi mais frequente, a dominância da espécie Limnothrix planctonica coincidiu com o aumento da transparência da água. Isso pode ter ocorrido porque apesar de ser bem adaptada a ambientes com limitação de luz, a densidade dessa espécie aumenta com a intensidade luminosa, o que ocorre quando há aumento da transparência da água (OLIVEIRA et al., 2019). Esse resultado também foi observado em 2015 quando a análise de CCA mostrou forte correlação entre esta espécie e o aumento da transparência, principalmente nos meses de junho e julho, mesmo período em que foi detectada a presença de microcistina-LR na água bruta e tratada da ETAm (OLIVEIRA et al., 2019).

Esses resultados apontam para a necessidade da implementação de um plano de monitoramento da densidade de cianobactérias na Estação de Tratamento de Água de Macapá (ETAm). Além disso deve-se realizar também o monitoramento da presença de cianotoxinas na água, uma vez que o estudo realizado em 2015 na área CAESA detectou a presença de microcistina-LR (cianotoxina) quando a densidade de cianobactérias era sete vezes menor que a registrada em 2019 (OLIVEIRA et al., 2019). Portanto, pode-se inferir que se a densidade de células aumentou ao longo dos anos, a concentração dessas cianotoxinas também deve ter aumentado. Com efeito, o monitoramento se faz ainda mais necessário, atentando-se para o tratamento da água, uma vez que a companhia utiliza o tratamento convencional, com procedimentos de floculação, decantação, filtração, desinfecção e fluoretação (OLIVEIRA et al., 2019). Alguns desses métodos podem não ser eficientes quando as densidades de células e cianotoxinas forem elevadas, como por exemplo, no caso de uma floração (HITZFELD et al., 2000). O monitoramento pode fornecer informações importantes para a adequação do tratamento em caso de florações.

O aumento da densidade de células de cianobactérias na ETAm gera um alerta e preocupação devido aos riscos associados que as cianotoxinas podem oferecer à saúde pública. Entretanto apesar do método de contagem ser bastante útil para avaliar a densidade de células na água, e com isso prever possíveis problemas que as mesmas possam oferecer, a contagem de células não fornece informações detalhadas acerca da presença e, principalmente, da concentração de toxinas na água (BURATTI et al., 2017). Com base nestas premissas, são necessários também estudos específicos que permitam o isolamento das cepas para que organismos potencialmente tóxicos possam ser identificados, e também estudos sobre a concentração de cianotoxinas. 


\section{CONCLUSÕES}

A densidade do fitoplâncton foi considerada baixa durante o período de monitoramento. Este trabalho mostrou a ocorrência de uma variação sazonal dos grupos do fitoplâncton, sendo as diatomáceas mais abundantes em períodos menos chuvosos, e as cianobactérias na transição do período chuvoso para o período menos chuvoso.

Em relação às cianobactérias, foi observado que existe uma tendência anual de aumento da densidade de cianobactérias entre os períodos de maio a agosto, quando a transparência da água se torna o parâmetro com maior influência sobre o grupo. Tanto que ocorreu um aumento acentuado na densidade de cianobactérias em junho de 2019 (7x maior do que a quantidade registrada em anos anteriores). Apesar dos resultados observados ainda estarem em conformidade com o estabelecido pelo Ministério da Saúde, esses valores são preocupantes e apontam para necessidade urgente de um plano de monitoramento de cianobactérias na água bruta da ETAm. Com isso será possível evitar problemas futuros, tais como a produção de odor, sabor à água e principalmente potenciais intoxicações humanas.

\section{REFERÊNCIAS}

ABREU, C. H. M.; BARROS, M. L. C.; BRITO, D. C.; TEIXEIRA, M. R.; CUNHA, A. C.. Hydrodynamic modeling and simulation of water residence time in the Estuary of the Lower Amazon River. Water, v.12, p.1/60-30, 2020. DOI:

http://dx.doi.org/10.3390/w12030660

AZEVEDO, S. M. F. O.; CARMICHAEL, W. W.; JOCHIMSEN, E. M.; RINEHART, K. L.; LAU, S.; SHAW, G. R.; EAGLESHAM, G. K.. Human intoxication by microcystins during renal dialysis treatment in Caruaru - Brazil. Toxicology, v.181, p.441-446, 2002. DOI: https://doi.org/10.1016/S0300-483X(02)00491-2

BICUDO, C. E. M.; MENEZES, M.. Gêneros de Algas de Águas Continentais do Brasil. 2 ed. São Carlos: Rima, 2006.

BICUDO, D. C.; TREMARIN, P.; ALMEIDA, P. D.; ZORZALALMEIDA, S.; WENGRAT, S.; FAUSTINO, S. B.; COSTA, L. F.; BARTOZEK, E. C. R.; ROCHA, A. C. R.; BICUDO, C. E. M.; MORALES, E. A.. Ecology and distribution of Aulacoseira species (Bacillariophyta) in tropical reservoirs from Brazil. Diatom Research, v.31, n.3, p.199-215, 2016. DOI: https://doi.org/10.1080/0269249X.2016.1227376

BORGES, P.; TRAIN, S.; RODRIGUES, L.. Spatial and temporal variation of phytoplankton in two subtropical Brazilian reservoirs. Hydrobiologia, Maringa, v.607, n.1, p.63-74, 2008. DOI: https://doi.org/10.1007/s10750-008-9367-3

BRAAK, C. J. F. T.; VERDONSCHOT, P. F. M.. Canonical correspondence analysis and related multivariate methods in aquatic ecology. Aquatic Sciences, v.57, n.3, p.255-289, 1995. DOI: http://doi.org/10.1007/bf00877430

BRASIL. Avaliação da Vigilância da Qualidade da Água no Estado do Amapá: Ano base 2011. Brasília, 2012.

BRASIL. Portaria de Consolidação n. 5 de $\mathbf{2 8}$ de setembro de 2017. Consolidação das normas sobre as ações e os serviços de saúde do Sistema Único de Saúde. Brasília: DOU, 2017.
BRASIL. Resolução 357/2005, de 17 de março de 2005.

Dispõe sobre a classificação dos corpos de água e diretrizes ambientais para o seu enquadramento. Brasília: DOU, 2005.

BURATTI, F. M.; MANGANELLI, M.; VICHI, S.; STEFANELLI, M.; SCARDALA, S.; TESTAI, E.; FUNARI, E.. Cyanotoxins: producing organisms, occurrence, toxicity, mechanism of action and human health toxicological risk evaluation. Archives of Toxicology, v.91, p.1049-1130, 2017. DOI: https://doi.org/10.1007/s00204-016-1913-6

CALIJURI, M. C.; ALVES, M. S. A.; SANTOS, A. C. A. Cianobactérias e Cianotoxinas em Águas Continentais. Rima, 2006.

CETESB. Companhia Ambiental do Estado de São Paulo. Manual de Cianobactérias Planctônicas: Legislação, Orientações para o Monitoramento e Aspectos Ambientes. São Paulo: CETESB, 2013.

CETESB. Companhia Ambiental do Estado de São Paulo. Norma Técnica L5. 303: Fitoplâncton de Água Doce-Métodos Qualitativo e Quantitativo. São Paulo: CETESB, 2012.

COSTA-BODDEKER, S.; BENNION, H.; JESUS, T. A.; ALBUQUERQUE, A. L.; FIGUEIRA, R. C. L.; BICUDO, D. C.. Paleolimnologically inferred eutrophication of a shallow, tropical, urban reservoir in southeast Brazil. J. Paleolimnol. São Paulo, v.48, p.751-766, 2012. DOI: https://doi.org/10.1007/s10933-012-9642-1

CUNHA, A. C.; CUNHA, H. F. A.; SOUZA, J. A.; NAZARÉ, A. S.; PANTOJA, S.. Monitoramento de Águas Superficiais em Rios Estuarinos do Estado do Amapá sob Poluição Microbiológica. Bol. Museu Paraense Emílio Goeldi, v.1, n.1, p.191-199, 2005.

CUNHA, A.; CUNHA, H.; JÚNIOR, A. C.; DANIEL, L.; SCHULZ, H.. Qualidade microbiológica da água em rios de áreas urbanas e periurbanas no baixo amazonas: o caso do Amapá. Engenharia Sanitária e Ambiental, v.9, n.4, p.322-328, 2004. 
CUNHA, E. D. S.; CUNHA, A. C.; SILVEIRA JUNIOR, A. M.; FAUSTINO, D. M. M.. Phytoplankton of two rivers in the eastern Amazon: characterization of biodiversity and new occurrences. Acta Botanica Brasilica, v.27, n.2, p.364-377, 2013. DOI: https://doi.org/10.1590/S010233062013000200011

DAMASCENO, M. S.; RIBEIRO, H. M. C.; TAKIYAMA, L. R.; PAULA, M. T.. Avaliação sazonal da qualidade das águas superficiais do Rio Amazonas na orla da cidade de Macapá, Amapá, Brasil. Rev. Ambiente e Água, Taubaté, v.10, n.3, p.599-613, 2015.

ESTEVES, F. A.. Fundamentos de Limnologia. 3 ed. Rio de Janeiro: Interciência, 2011.

FISHER, T. R.. Plâncton e produção primária em sistemas aquáticos da bacia da Amazônia Central. Acta Amazônica, v.8, n.4, p.43-54, 1978.

FUNASA. Manual de controle da qualidade da água para técnicos que trabalham em ETAS. Brasília: FUNASA, 2014.

HE, G.; PAN, Y.; TANAKA, T.. The short-term impacts of COVID-19 lockdown on urban air pollution in China. Nature Sustainability, v.3, p.1005-1011, 2020. DOI: https://doi.org/10.1038/s41893-020-0581-y

HITZFELD, B. C.; HÖGER, S. J.; DIETRICH, D. R.. Cyanobacterial Toxins: Removal during Drinking Water Treatment, and Human Risk Assessment. Environmental Health Perspectives, v.108, p.113-122, 2000.

JUN, H.; LEE, Y.; LEE, B.; KNAPPE, D. R. U.. Effectiveness of coagulants and coagulant aids for the removal of filterclogging Synedra. Journal of Water Supply: Research and Technology, v.50, n.3, p.135-148, 2001. DOI: https://doi.org/10.2166/aqua.2001.0013

JUNK, W. J.; PIEDADE, M. T. F.; SCHÖNGART, J.; COHN-HAFT, M.; ADENEY, J. M.; WITTMANN, F.. A classification of major naturally-occurring Amazonian Lowland wetlands. Wetlands, v.31, n.4, p.623-640, 2011. DOI:

https://doi.org/10.1007/s13157-011-0190-7

OKSANEN, J.. Constrained ordination: tutorial with $\mathrm{R}$ and vegan. 2012.

OLIVEIRA, E. D. C.; CUNHA, A. C.; SILVA, N.; BRANCO, R.; MORAIS, J.; SCHNEIDER, M. P.; FAUSTINO, S. M. M.; RAMOS, V.; VASCONCELOS, V.. Morphological and molecular characterization of cyanobacterial isolates from the mouth of the Amazon River. Phytotaxa, v.387, n.4, p.269-288, 2019. DOI: https://doi.org/10.11646/phytotaxa.387.4.1

OLIVEIRA, E. D. C.; BRANCO, R.; SILVA, L.; SILVA, N.; AZEVEDO, J.; VASCONCELOS, V.; FAUSTINO, S.; CUNHA, A.. First Detection of Microcystin-LR in the Amazon River at the Drinking Water Treatment Plant of the Municipality of Macapá, Brazil. Toxins, v.669, n.11, p-2-21, 2019b. DOI: https://doi.org/10.3390/toxins11110669

PEREIRA, L. D. A.. Saber ecológico: o Fitoplâncton e nossas águas. Dissertação (Mestrado Profissional em Ensino de
Ciências e Matemática) - Pontifícia Universidade Católica de Minas Gerais, Belo Horizonte, 2013.

PINHEIRO, L. A. R.; CUNHA, A. C.; CUNHA, H. F. A. C.; SOUZA, L. R.; BILHALVA, J. S.; BRITO, D. C.; BRASIL JÚNIOR, A. C. P. Aplicação de simulação computacional à dispersão de poluentes no baixo rio Amazonas: Potenciais riscos à captação de água na orla de Macapá-Amapá. Amazônia: Ciência e Desenvolvimento, v.4, n.7, p.27-44, 2008.

POURIA, S.; ANDRADE, A.; BARBOSA, J.; CAVALCANTI, R. L.; BARRETO, V. T.; WARD, C. J.; PREISER, W.; POON, G. K.; NEILD, G. H.; CODD, G. A.. Fatal microcystin intoxication in haemodialysis unit in Caruaru, Brazil. The Lancet, v.352, p.21-26, 1998. DOI: https://doi.org/10.1016/S01406736(97)12285-1

\section{R DEVELOPMENT CORE TEAM.. A Language and}

Environment for Statistical Computing. R Development Core Team, 2017.

REYNOLDS, C.. Ecology of Phytoplankton. Ecology, Biodiversity and Conservation. Cambridge: Cambridge University Press, 2006.

ROSE, A. K.; KINDER, J. E.; FABBRO, L.; KINNEAR, S.. A phytoplankton risk matrix: combining health, treatment, and aesthetic considerations in drinking water supplies.

Environment Systems and Decisions, v.39, p.163-182, 2018. DOI: https://doi.org/10.1007/s10669-018-9711-8

SILVA, N.; LOPES, J. O.; BRITO, J. D. M.; SANTOS, S. K.; TAKIYAMA, L. R.; MONTAGNER, A. E. A. D.; OLIVEIRA, E. D. C. Diagnóstico da qualidade da água em áreas utilizadas pela Bubalinocultura no Baixo Araguari, Amapá, Brasil. Biota Amazônica, Macapá, v.8, n.1, p.22-28, 2018.

SIOLI, H.. Amazônia: Fundamentos da Ecologia da Maior Região de Florestas Tropicais. Instituto Max-Planck de Limnologia, 1985.

SIOLI, H.. The Amazon and its main affluents: Hydrography, morphology of the river courses, and river types. In: The Amazon. Dordrecht, 1984. p.127-165.

SMITH, V. H.; SCHINDLER, D. W.. Eutrophication Science: where do we go from here?. Cell Press, v.24, n.4, p.201-207, 2009. DOI: https://doi.org/10.1016/j.tree.2008.11.009

SMITH, V. H.; TILMAN, G. D.; NEKOLA, J. C.. Eutrophication: impacts of excess nutrient in puts on freshwater, marine, and terrestrial ecosystems. Environmental Pollution, v.100, p-179-196, 1999. DOI: https://doi.org/10.1016/S02697491(99)00091-3

SOARES, M. C.; SOPHIA, M. G.; HUSZAR, V. L. M..

Phytoplankton flora of two rivers in Southeast Brazil: Paraibuna and Pomba Rivers. Revista Brasileira de Botânica, v.30, n.3, p.433-450, 2007.

YUNUS, A. P.; MASAGO, Y.; HIJIOKA, Y.. COVID-19 and surface water quality: Improved lake water quality during the lockdow. Science of the Total Environment, v.731, p, 28, 2020. DOI: https://doi.org/10.1016/j.scitotenv.2020.139012

A CBPC - Companhia Brasileira de Produção Científica (CNPJ: 11.221.422/0001-03) detém os direitos materiais desta publicação. Os direitos referem-se à publicação do trabalho em qualquer parte do mundo, incluindo os direitos às renovações, expansões e disseminações da contribuição, bem como outros direitos subsidiários. Todos os trabalhos publicados eletronicamente poderão posteriormente ser publicados em coletâneas impressas sob coordenação da Sustenere Publishing, da Companhia Brasileira de Produção Científica e seus parceiros autorizados. Os (as) autores (as) preservam os direitos autorais, mas não têm permissão para a publicação da contribuição em outro meio, impresso ou digital, em português ou em tradução. 